\title{
Influence of crop geometry and cultivars on growth, yield and production efficiency of dry direct-seeded rice (Oryza sativa L.)
}

\author{
Sandeep Kumar ${ }^{1,2 *}$, Manoj Kumar Singh ${ }^{1}$, Ram Swaroop Meena ${ }^{1,3}$ and Kiran Hingonia ${ }^{1,4}$ \\ ${ }^{1}$ Department of Agronomy, Institute of Agricultural Sciences, Banaras Hindu University, Varanasi-221005, (UP) INDIA \\ ${ }^{2}$ CCS Haryana Agricultural University Hisar - 125004 (Haryana), INDIA \\ ${ }^{3}$ The Ohio State University, C-MASC, 422C Kottman Hall, 2021 Coffey Road, Columbus, OH 43210, USA \\ ${ }^{4}$ Department of Agronomy, PalliSiksha Bhavana, Institute of Agriculture Science, Visva-Bharati, Sriniketan, Kolkata- \\ 731236 (West Bengal), INDIA \\ *Corresponding author. Email: sandeepsihag1992@gmail.com
}

Received: August 21, 2016; Revised received: May 14, 2017; Accepted: November 6, 2017

\begin{abstract}
A field experiment was conducted during kharif (summer) season of 2014, aim of the experiment was to investigate suitable crop geometry and cultivar and their influences on performance of dry direct-seeded rice (Oryza sativa L.), experimental treatments were consisting of 15 treatments, namely, main plots: five cultivars (MTU 7029, NDR 97, HUR 105, HUR 4-3 and PRH-10) and sub-plots: three crop geometry's $\left(20 \times 10,20 \times 20\right.$ and $\left.25 \times 25 \mathrm{~cm}^{2}\right)$. All the data recorded were statistically analyzed using the standard procedures of split-plot design. The results indicated that amongst cultivars, aromatic rice hybrid $\mathrm{PRH}-10$ recorded significantly more grain yield $(5582.32 \mathrm{~kg} /$ ha) than cultivar HUR 4-3 (4612.99 kg/ha) and NDR 97 (3397.82 kg/ha), whereas; it was statistically comparable with cultivar MTU $7029(5489.24 \mathrm{~kg} / \mathrm{ha})$ and HUR $105(5022.03 \mathrm{~kg} / \mathrm{ha})$. The cultivar PRH-10 also registered higher gross return (105771.9 ₹/ha), net return (66389.08 ₹/ha) and production efficiency (592.76 ₹/ha/day) than the remaining cultivars. The higher grain yield of $\mathrm{PRH}-10$ over these cultivars was due to considerable improvement in most of its yield attributing characters like panicle length $(27.92 \mathrm{~cm})$, a number of grains/panicle (178.70) and test weight $(26.35 \mathrm{~g})$. In a case of crop geometry treatment, plant spacing of $25 \times 25 \mathrm{~cm}^{2}$ recorded higher grain yield as compared to remaining plant spacing while the plant spacing of $20 \times 10 \mathrm{~cm}^{2}$ recorded higher gross return, net return and production efficiency as compared to $20 \times 20$ and $25 \times 25 \mathrm{~cm}^{2}$. Plant geometry plays an imperative role towards improving the grain yield of cultivars in direct seeded rice by optimal utilization of natural resources. Therefore, for getting higher net return and production efficiency, cultivar $\mathrm{PRH}-10$ at plant spacing $20 \times 10 \mathrm{~cm}^{2}$ can be raised in dry direct-seeded rice in Varanasi region of Eastern Uttar Pradesh.
\end{abstract}

Keywords: Crop geometry, Cultivar, Direct seeded rice, Economics, Production efficiency, Yield

\section{INTRODUCTION}

Rice (Oryza sativa L.) is a staple food for over $50 \%$ of the world's population. It is grown in approximately 114 countries across the world on an area of 161.03 million hectares with annual production of 478.73 million tonnes having a productivity of $44.3 \mathrm{q} / \mathrm{ha}$ during $2014-$ 15 (FAO, 2016) accounting about $11 \%$ of the world's cultivated land. Rice is the key crop in India's food security accounting about $44 \%$ of the total food grain production (Anonymous, 2010). It is the major source of energy providing $43 \%$ calorie requirement for over $70 \%$ of Indians and occupied 43.86 million hectares of cultivated area with annual production of 105.48 million tonnes having a productivity of $24.24 \mathrm{q} /$ ha during 2014 -15 (Indiastat, 2016). Of this, more than $70 \%$ rice is grown under a rainfed condition, $9 \%$ under upland and $21 \%$ under partially or fully irrigated conditions.

According to estimation, by 2025, the world's farmers need to produce about $60 \%$ more rice than at present to meet the food demands of the expected world population at that time. Therefore, this extra rice production needed has to come from a productivity gain. The major challenge is to achieve this gain with less water, labor and energy, thereby ensuring long-term environmental sustainability along with two major challenges, first, it needs to enhance food production sustainably to feed a growing world population; at the same time, this increase needs to be accomplished under conditions of increasing scarcity of water resources (Dadhich and Meena, 2015; Meena et al., 2015). Therefore, under his situation, dry direct seeding is an appropriate alternative method of rice raising which offers such advantages as faster as easier planting, reduced labor, lesser water need, earlier crop maturity, less methane emission and often higher profitability (Thiyagarajan et al., 2002; Uphoff, 2007; Krishna et al., 2008).

Among the available higher production technology 
selection of appropriate high yielding cultivar according to specific location and region at suitable crop geometry is imperative phenomena for boosting production of dry direct-seeded rice (DSR). As the seed of rice hybrids are expensive, therefore, selection of ideal crop geometry must to adopt for getting optimum plant stand in the field which results in higher growth and yield attributes. The same genotype do not perform equally good in all the growing ecosystem hence through selection of appropriate rice cultivar; the growth and yield potential, yield attributes as well as the economics and production efficiency of rice can be improved in direct seeded conditions (Meena et al., 2013; Meena and Yadav, 2015). Hybrid vigor in rice is profitably used to increase its productivity by $14-28 \%$ over the available best cultivars in India (Siddiqui, 1993). Crop geometry plays a significant role in optimization of rice yield due to efficient utilization of solar radiation as well as nutrients in direct seeded conditions (Siddiqui et al., 1999). A planting density that can bring down the seed requirement without sacrificing productivity would go a long way in popularizing the direct seeded rice cultivation. The increase in plant population above optimum may decrease crop yield while on another side yield may also reduce due to lesser plant population below optimum due to inability to intercept maximum available light by poor plant stand (Mahajan et al., 2010). Closer spacing hampers intercultural operations and as such more competition arises among the crop plants for nutrients, $\mathrm{CO}_{2}$ and light. As a result, the plant becomes weaker and thinner producing lower growth and yield attributes. In contrast, at lower plant population these factors are not well utilized. Plant to plant and row to row spacing had a significant effect on growth, yield and yield attributing characters of direct seeded rice (Sultana et al., 2012). The plant geometry and spatial configuration exploit the initial vigor of the genotypes with enhanced soil aeration creating a congenial condition for better establishment (Shukla et al., 2014). However, at present, the information of appropriate spacing and cultivar of rice is not well known in direct seeded condition. Keeping in mind, the present investigation was carried out to determine suitable cultivar and optimum crop geometry towards a profitable production of rice (Oryza sativa L.) under dry direct seeded conditions.

\section{MATERIALS AND METHODS}

Experimental site: The present field experiment was conducted during kharif season of 2014 at Agronomy farm of Banaras Hindu University, Varanasi, Uttar Pradesh, which is situated at $25^{\circ} 18^{\prime} \mathrm{N}$ latitude, $83^{\circ} 03^{\prime}$ E longitude and altitude of $81.71 \mathrm{~m}$ meters above mean sea level. This region comes under agro-climatic zone III A (Semi-Arid Eastern Plain Zone), and the region is mostly rainfed (Meena et al., 2016).
Treatments detail: The experiment was laid out in split plot design with three replications. The different cultivars (5) were allocated in main plots and crop geometry (3) in subplots. The five cultivars used were Swarna (MTU 7029), Narendra Dhan 97 (NDR 97), Malviya Sugandhit Dhan 105 (HUR 105), HUR 43,Pusa Rice Hybrid 10 (PRH-10) and three crop geometry $20 \times 10 \mathrm{~cm}^{2}$ (50 hills $\left./ \mathrm{m}^{2}\right), 20 \times 20 \mathrm{~cm}^{2}(25$ hills $\left./ \mathrm{m}^{2}\right)$ and $25 \times 25 \mathrm{~cm}^{2}\left(16 \mathrm{hills} / \mathrm{m}^{2}\right)$. Pusa Rice Hybrid-10 (PRH-10) is the first superfine grain aromatic hybrid with basmati like quality developed at IARI, New Delhi, in 1998 from the cross of Pusa 6A x PRR-78. The grains are fine and medium-long with a test weight of 22-24 g. It is a medium-duration hybrid which matures in 110-115 days. The cultivar MTU 7029 was released in 1982 from Acharya NG Ranga Agricultural University, Andhra Pradesh, India from the cross of Vasista x Mahsuri. It is a dwarf cultivar with medium slender grain, long duration cultivar which matures in about 140 days. The Narendra Dhan 97 (NDR 97) was produced by crossing Nagina $22 \mathrm{x}$ Ratna in 1992 from Narendra Deva University of Agricultural \& Technology, Faizabad, Uttar Pradesh, India. This is a short duration early maturing cultivar with medium slender grains. The cultivar HUR 4-3 and HUR 105 are mutant of Lanjhi and MPR7-2, respectively, released from Banaras Hindu University, Varanasi, Uttar Pradesh, India in 2009. These have long slender grain. Both of these (HUR 4-3 and HUR 105) are semi-dwarf cultivars with an average plant height of $90-100 \mathrm{~cm}$ and $100-102 \mathrm{~cm}$, respectively and mature in 135-140 and 130-135 days, respectively.

Physico-chemical properties of experimental soil: The soil of the experimental field was 'sandy clay loam', neutral in reaction ( $\mathrm{pH} 7.3$ ), having $0.47 \%$ organic carbon (Walkley and Black method, 1947; Jackson, 1973), $207.5 \mathrm{~kg} / \mathrm{ha}$ available N (Alkaline permanganate method, AOAC, 1967), medium levels of available phosphorus $(21.5 \mathrm{~kg} / \mathrm{ha}$, Olsen's method, Jackson,1973) and available potassium (223.6 kg/ha, Flame Photometer method, Jackson, 1973) in 0-15 cm soil depth at the start of the experiment. Indian soils have been characterized into three classes, i.e. low, medium and high levels of a particular nutrient depending upon the fertility prestige (Prasad et al., 2006).

General agronomic practices: The crop was direct seeded under un-puddled un-ponded plots on 27 June 2014. One to two seeds were dropped in each hole of 4 $-5 \mathrm{~cm}$ depth as per the spacing treatment. To maintain uniform plant population, thinning and gap filling was done after two weeks of sowing. Nitrogen was applied at two levels; i.e., 150 (for PRH-10) and $120 \mathrm{~kg} \mathrm{~N} / \mathrm{ha}$ for remaining cultivars. Urea, an organic fertilizer containing $46 \% \mathrm{~N}$ was applied as per requirement of treatments in three splits, viz. (i) $50 \% \mathrm{~N}$ as a basal application at the time of sowing (ii) $25 \% \mathrm{~N}$ at tillering 
stage and (iii) $25 \%$ at panicle initiation stage of the crop. Phosphorus (80 kg $\mathrm{P}_{2} \mathrm{O}_{5} /$ ha for PRH-10 and 60 $\mathrm{kg} \mathrm{P}_{2} \mathrm{O}_{5} /$ ha for remaining cultivars) as DAP, a complex fertilizer containing $46 \% \mathrm{P}_{2} \mathrm{O}_{5}$ and $18 \% \mathrm{~N}$ and potash (60 $\mathrm{kg} \mathrm{K} \mathrm{K}_{2} \mathrm{O} / \mathrm{ha}$ for PRH-10 and $40 \mathrm{~kg} \mathrm{~K} \mathrm{~K}_{2} \mathrm{O} / \mathrm{ha}$ for remaining cultivars) as muriate of potash (contains $60 \% \mathrm{~K}_{2} \mathrm{O}$ ) were applied uniformly in all plots at the time of final land preparation. A foliar spray of zinc sulfate (contains $21 \% \mathrm{Zn}$ ) and lime mixture (un-slacked) prepared by mixing $5.0 \mathrm{~kg} \mathrm{ZnSO} 4.7 \mathrm{H}_{2} \mathrm{O}$ $+2.5 \mathrm{~kg} \mathrm{CaCO}_{3}$ with 500 liters water per ha was applied when $\mathrm{Zn}$ deficiency symptoms (brown spots on young leaves) appear at 35 DAS to protect the crop from Khaira disease. For management of weeds flora bispyribac Na@25 g/ha was foliar sprayed at 15 DAS followed by a manual weeding at 40 DAS when the soil moisture was sufficient for easy weed removal from the soil. The irrigation was given as per the crop requirement and rainfall pattern.

The procedure of observations: Leaf area index (LAI) values were taken at 30,60 and 90 DAS (days after sowing) with the help of crop canopy analyzer. First, the total area of a leaf was measured by keeping the sensor of canopy analyzer over the crop canopy and then the ground area was recorded by keeping the sensor over the soil surface. Thus, an output of automatic LAI reading was obtained. From a plot, LAI reading was taken from five random places and their average leaf area index was worked out. Chlorophyll content in green functioning leaves was determined with SPAD meter at 60 and 90 DAS by selecting 15 healthy green leaves from different plants from each plot randomly, and an average of them was worked out. A number of tillers bearing panicle were counted in a meter square area with the help of $1 \times 1 \mathrm{~m}^{2}$ quadrate in each plot separately. Ten panicles were selected from randomly tagged plants from each plot at the time of harvest to determine the number of grains per panicle, panicle length and test weight (1000-grain weight). Since the duration of the five cultivars differed they were harvested at different periods. The cultivar NDR 97, PRH-10, HUR 105, HUR 4-3 and MTU 7029 were harvested on 30 September, 18 December, 4 November, 8 November and 20 November 2014 , respectively. The net plots were harvested after removing the border rows and were tied, numbered and left out in the field to dry for 4-5 days. After proper cleaning and winnowing the grain weight of each plot at $14 \%$ moisture was recorded.

Weather during experiment: Rice is basically a crop of warm regions of the tropics and subtropics. The overall performance of crop was good; due to an optimum range of all parameters for favorable weather condition during the monsoon season of 2014. The mean maximum and minimum temperature during the whole crop growth period was 32.13 and $22.84^{\circ} \mathrm{C}$ while the mean maximum and minimum relative humidity were 84 and $60.4 \%$, respectively (Fig. 1). All the data recorded were statistically analyzed using the standard procedures of split-plot design (Gomez and Gomez, 1984). Analysis of variance (ANOVA) was used to determine the influence of all treatment. Once F ratio was significant, a multiple mean comparison was performed using Fisher's Least Significance Difference Test (0.05 probability level).

\section{RESULTS AND DISCUSSION}

Effect of cultivars: The present study showed that the superfine grain aromatic hybrid Pusa Rice Hybrid 10 (PRH-10) maintained its significant superiority in morphological parameters i.e. plant height $(119.73 \mathrm{~cm})$, number of leaves $/ \mathrm{m}^{2}$ (305.89 and 2058.11 at 30 and 60 DAS, respectively) (except at 90 DAS), and leaf area index (0.36 and 4.31 at 30 and 60 DAS) (except at 90 DAS) as compared to other rice cultivars under direct seeded conditions (Table 1). MTU 7029 recorded significantly higher number of leaves $/ \mathrm{m}^{2}(1715.78)$ at 90 DAS than remaining cultivars. However, the LAI at 90 DAS in PRH-10 (4.64) was higher than other cultivars, but it was at par with MTU 7029 (4.22). In contrast, the number of leaves $/ \mathrm{m}^{2}$ continued to increase up to 60 DAS after that decreased in all the cultivars except in MTU 7029, in which from 60 DAS (1650.22) to 90 DAS (1715.78) slight increment was noticed. All the cultivars in the study recorded maximum LAI value during flowering stage (90 DAS). However, at 90 DAS, the cultivar NDR 97 registered lower LAI indicating its physiological maturity at this stage. MTU 7029 (42.71 and 42.04) mentioned significantly higher chlorophyll content in functioning leaves during the entire period of observations than the HUR 105 (36.36 and 34.38), HUR 4-3 (38.69 and 35.44) and NDR 97 (36.98at 90 DAS) at 30 and 60 DAS, respectively while NDR 97 at 60 DAS (40.53) and PRH-10 at 60 (41.37) and 90 DAS (40.88) had statistically comparable chlorophyll content with MTU 7029 (Table 1). The plant height, number of leaves (at 30 and 90 DAS) and LAI of rice hybrid PRH-10 was more than inbred cultivars due to more number of tillers $/ \mathrm{m}^{2}$ as well as wider and longer leaves or might be due to better utilization of available natural resources like photoperiod and temperature for growth and development which may result in more nitrogen absorption for the synthesis of protoplasm responsible for rapid cell division which may increase the plant in shape and size or may be due to genetical characters of the cultivar (Kumar et al., 2002; Adhikari et al., 2004; Gautam et al., 2008; Meena et al., 2015). Rice hybrids show hetero-biltios is for leaves production due to higher tillers per plant. The same higher value of LAI was also reported in rice hybrid at heading stage by Yang et al. (2001). The higher chlorophyll content in cultivar MTU 7029 was due to the genetic character of the cultivar. Statistically similar chlorophyll content in 
hybrid cultivar PRH-10 and MTU 7029 may be due to the fact that cultivar PRH-10 accumulate higher nitrogen from the soil than the other cultivars and chlorophyll content in leaves is directly associated with nitrogen uptake.

The rice hybrid PRH-10 registered significantly longer panicles $(27.92 \mathrm{~cm})$, more number of grains/panicle (178.70), test weight (26.35 g) and harvest index (53.25) than the remaining tested cultivars (Table 2a). Furthermore, the number of grains/panicle was statistically comparable in PRH-10 (178.70), HUR 4-3 (157.50) and MTU 7029 (153.50). The differences in test weight among HUR 105 (23.05 g), HUR 4-3 (22.15 g), NDR 97 (19.91 g) and MTU 7029 (18.62 g) were also significant, and it was in decreasing order. The cultivar MTU 7029 had more number of effective tillers $/ \mathrm{m}^{2}$ (289.67) than the rest of the cultivars. The higher values of yield attributes recorded by hybrid PRH-10 over inbred cultivars was associated with its higher number of tillers per unit area, better crop growth and development, higher photosynthetic efficiency due to higher LAI at flowering and also towards physiological maturity. Significantly higher harvest index in PRH-10 than the rest of the tested cultivars was due to the higher dry matter accumulation and consequently higher total biological yield. Similarly, grain yield in PRH-10 (5582.32 kg/ha) was significantly higher over cultivar HUR 4-3 (4612.99 kg/ha) and NDR 97 (3397.82 kg/ha) whereas; it was statistically comparable with MTU 7029 (5489.24 kg/ha) and HUR $105(5022.03 \mathrm{~kg} / \mathrm{ha})$. The straw yield of cultivar HUR 4-3 (5589.20 kg/ha) was significantly more over the cultivar PRH-10 (4924.01 kg/ha) and NDR 97 (4473.53 kg/ha), although; HUR 4-3 (5589.20 kg/ha), HUR 105 (5402.74 kg/ha) and MTU 7029 (5176.16 $\mathrm{kg} / \mathrm{ha}$ ) had non-significant straw yield. The higher grain yield of a hybrid over conventional cultivar was perceived mainly due to the heterosis effect (Virmani, 1996) or it was also due to the better formation of yield attributes i.e. test weight, panicle length and number of grains/panicle. The statistically comparable grain yield in MTU 7029 with PRH-10 was due to its significantly higher number of effective tillers per unit area over other cultivars.

Effect of crop geometry: Plant population as a consequence of different spacing treatment led to variation in growth attributes, yield attributes and finally grain yield due to inter and intra-plant competition for solar radiation, space, and nutrients (Gautam et al., 2008). Amongst different crop geometry, critical difference (CD) values at $p=0.05$ were used to determine the significance. Three plant spacing - $20 \times 10,20 \times 20$ and $25 \times 25 \mathrm{~cm}^{2}$ - revealed that closer spacing of $20 \times 10$ $\mathrm{cm}^{2}$ maintained it's significant superiority in producing relatively higher number of leaves $/ \mathrm{m}^{2}$ (320.87 and 2132.40 at 30 and 60 DAS, respectively) and leaf area index $(0.35,3.58$ and 3.89 at 30, 60 and $90 \mathrm{DAS}$, re-

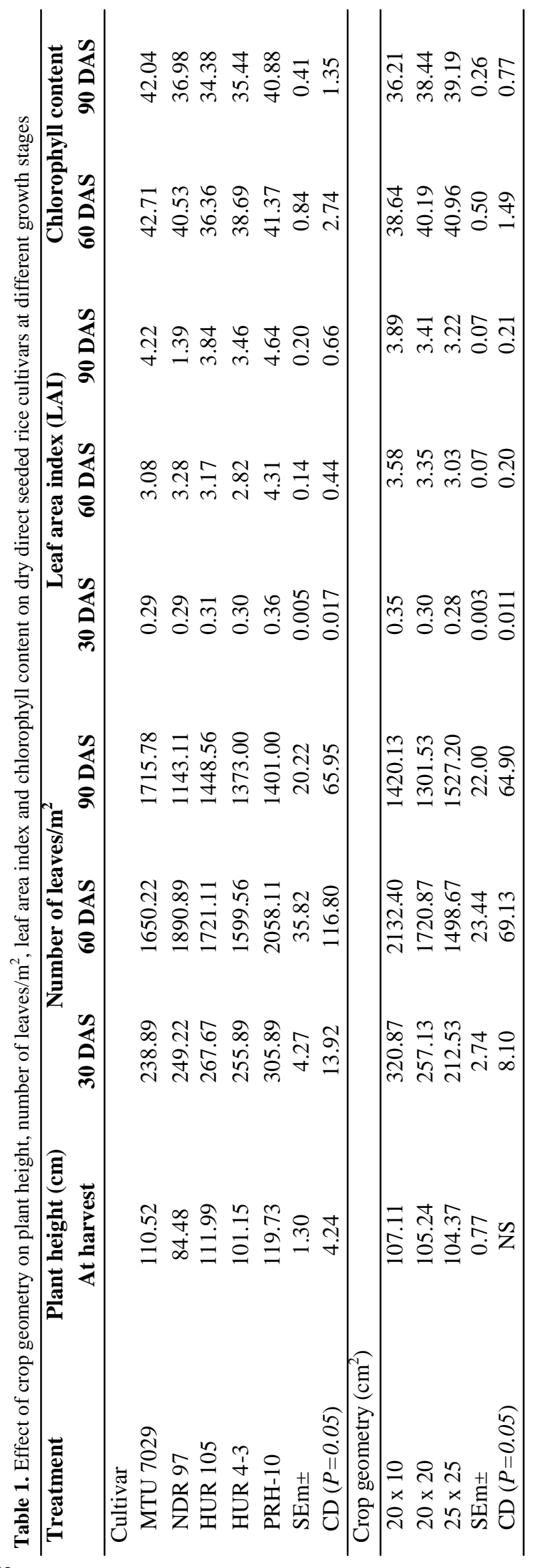


Sandeep Kumar et al. / J. Appl. \& Nat. Sci. 9 (4): 2469 - 2476 (2017)

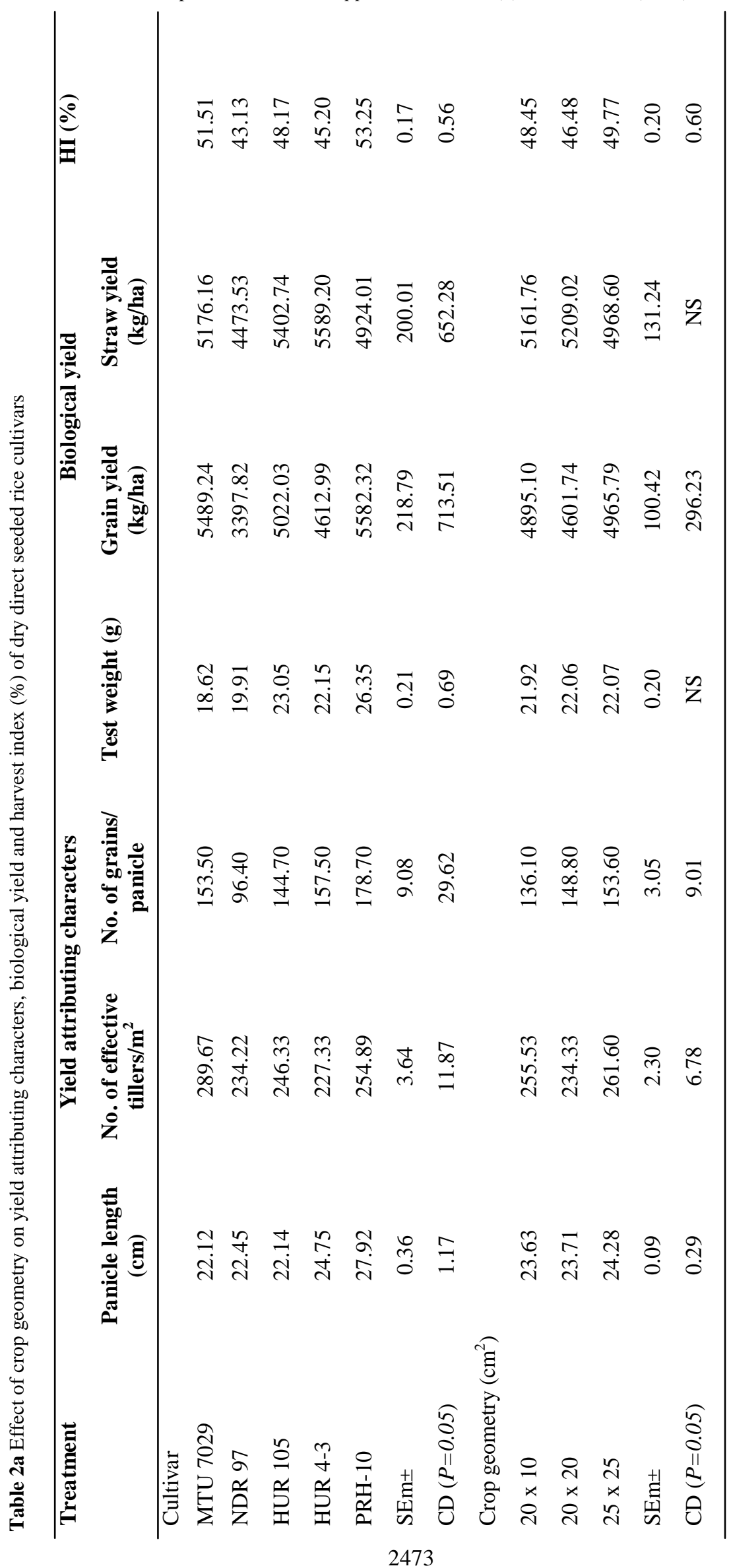




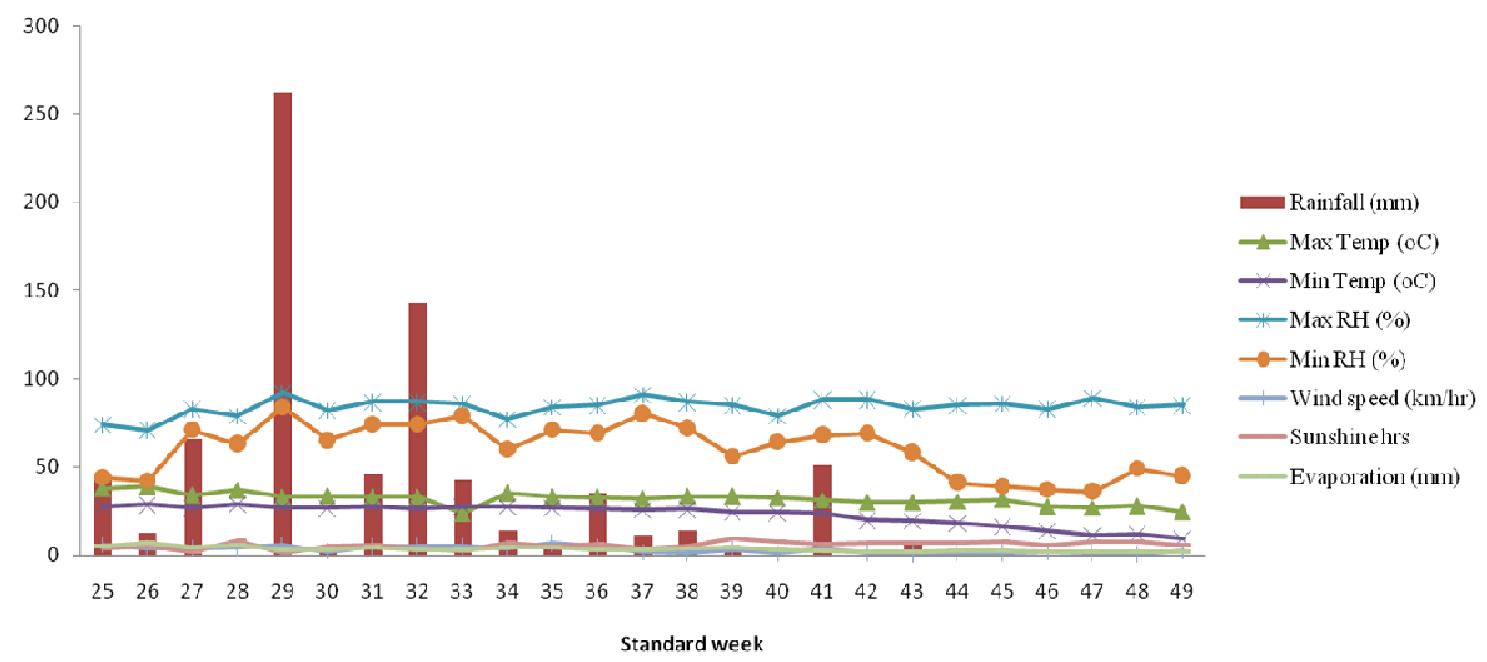

Fig. 1. Standard week wise Meterological observations recorded during the period of experimentation (June, 2014-Dec., 2014).

Table 2b. Interaction effect of crop geometry and cultivars on panicle length in dry direct seeded rice.

\begin{tabular}{lccccc}
\hline Treatment & \multicolumn{5}{c}{ Cultivars } \\
\hline Crop geometry $\left(\mathbf{c m}^{\mathbf{2}}\right)$ & MTU 7029 & NDR 97 & HUR 105 & HUR 4-3 & PRH-10 \\
\hline 20 x 10 & 21.72 & 21.55 & 22.13 & 24.98 & 27.75 \\
20 x 20 & 22.50 & 22.13 & 21.93 & 24.35 & 27.65 \\
25 x 25 & 22.13 & 23.67 & 22.35 & 24.92 & 28.35 \\
\hline \multicolumn{2}{r}{} & & SEm \pm & CD(P=0.05) \\
\hline Two plant geometry at the same cultivar & & 0.22 & 0.64 \\
Two cultivar means at the same or different plant geometry & & & 0.87 \\
\hline
\end{tabular}

spectively) over the square planting of $20 \times 20 \mathrm{~cm}^{2}$ and $25 \times 25 \mathrm{~cm}^{2}$ except the number of leaves $/ \mathrm{m}^{2}$ at 90 DAS (1527.20) as in wider spacing of $25 \times 25 \mathrm{~cm}^{2}$. The variations in plant height at harvest stage due to different crop geometry were non-significant. The maintenance of a significantly higher number of leaves $/ \mathrm{m}^{2}$ at $20 \mathrm{x}$ $10 \mathrm{~cm}^{2}$ over other spacing was due to higher plant population per unit area. An increase in a number of plants per unit area at a spacing of $20 \times 10 \mathrm{~cm}^{2}$ led to maintenance of a higher number of leaves as well as LAI than the wider spacing. The significant increase in number of leaves $/ \mathrm{m}^{2}$ at 90 DAS in wider spacing over remaining two spacing might be due to the higher mortality of tillers $/ \mathrm{m}^{2}$ associated with higher plant population that led to higher below and above ground competition for space, nutrient, water, air and light for performing normal physiological activities of the plant. Chlorophyll content in plant leaves increased with increase in plant geometry as in wider plant spacing of $25 \times 25 \mathrm{~cm}^{2}$ (40.96 and 39.19) and $20 \times 20 \mathrm{~cm}^{2}(40.19$ and 38.44) over narrow spacing of $20 \times 10 \mathrm{~cm}^{2}(38.64$ and 36.21) at 60 and $90 \mathrm{DAS}$, respectively; this might be due to the fact that with increase in plant spacing the inter and intra-plant competition for nutrients decreases and as a consequence plant accumulated more nitrogen as compared to closer plant spacing.
The significant increase in number of effective tillers/ $\mathrm{m}^{-2}$ at plant spacing $25 \times 25 \mathrm{~cm}^{2}(261.60)$ and $20 \times 10$ $\mathrm{cm}^{2}$ (255.53) was observed over spacing of $20 \times 20$ $\mathrm{cm}^{2}$ (234.33). However, a number of effective tillers/m ${ }^{-2}$ was at par between plant spacing of $25 \times 25 \mathrm{~cm}^{2}$ and $20 \times 10 \mathrm{~cm}^{2}$. The higher number of effective tillers $/ \mathrm{m}^{2}$ at $25 \times 25 \mathrm{~cm}^{2}$ spacing was due to lesser inter- and intra-plant competition for water, nutrient, light, and space. Direct seeding of rice cultivars at a wider spacing of $25 \times 25 \mathrm{~cm}^{2}$ resulted in significantly higher panicle length $(24.28 \mathrm{~cm})$, and a number of grains/ panicle(153.60) as compared to narrow plant spacing $20 \times 10 \mathrm{~cm}^{2}$ (Table $2 \mathrm{a}$ ). Interaction effect of cultivars and spacing revealed the significantly longer panicles with cultivar PRH-10 at $25 \times 25 \mathrm{~cm}^{2}(28.35 \mathrm{~cm})$ plant geometry over other cultivar and plant geometry interaction except for cultivar PRH-10 at $20 \times 10 \mathrm{~cm}^{2}$ $(27.75 \mathrm{~cm})$ with which it was not significant (Table b). The appreciable augmentation in yield ascribing characters of dry direct-seeded rice cultivars at wider spacing was due to better utilization of space, solar radiation and other inputs resulting in more panicle length and number of grains/panicle as compared to closer spacing. Furthermore, at closer plant spacing higher dry matter accumulation might have limited the 
Table 3. Effect of crop geometry on economics and production efficiency of dry direct seeded rice cultivars

\begin{tabular}{|c|c|c|c|c|c|}
\hline \multirow[t]{2}{*}{ Treatment } & \multicolumn{4}{|c|}{ Economics } & \multirow{2}{*}{$\begin{array}{c}\text { Production } \\
\text { efficiency } \\
\text { (₹/ha/day) }\end{array}$} \\
\hline & $\begin{array}{c}\text { Cost of cultivation } \\
(₹ / \mathrm{ha})\end{array}$ & $\begin{array}{c}\text { Gross return } \\
(₹ / \mathrm{ha})\end{array}$ & $\begin{array}{l}\text { Net return } \\
(₹ / h a)\end{array}$ & B:C ratio & \\
\hline $\begin{array}{l}\text { MTU } 7029+20 \times 10 \\
\mathrm{~cm}^{2}\end{array}$ & 35466.53 & 84368.36 & 48901.83 & 1.38 & 346.82 \\
\hline MTU $7029+20 \times 20 \mathrm{~cm}^{2}$ & 35361.53 & 96100.36 & 60738.83 & 1.72 & 426.74 \\
\hline MTU $7029+25 \times 25 \mathrm{~cm}^{2}$ & 35291.53 & 97841.84 & 62550.31 & 1.77 & 436.40 \\
\hline $\mathrm{NDR} 97+20 \times 10 \mathrm{~cm}^{2}$ & 35211.53 & 66294.33 & 31082.80 & 0.88 & 335.43 \\
\hline NDR $97+20 \times 20 \mathrm{~cm}^{2}$ & 35136.53 & 53847.96 & 18711.43 & 0.53 & 199.77 \\
\hline NDR $97+25 \times 25 \mathrm{~cm}^{2}$ & 35086.53 & 65460.91 & 30374.38 & 0.87 & 321.99 \\
\hline HUR $105+20 \times 10 \mathrm{~cm}^{2}$ & 35361.53 & 96336.93 & 60975.40 & 1.72 & 482.65 \\
\hline HUR $105+20 \times 20 \mathrm{~cm}^{2}$ & 35256.53 & 84175.32 & 48918.79 & 1.39 & 386.20 \\
\hline HUR $105+25 \times 25 \mathrm{~cm}^{2}$ & 35186.53 & 87141.88 & 51955.35 & 1.48 & 408.03 \\
\hline HUR $4-3+20 \times 10 \mathrm{~cm}^{2}$ & 35361.53 & 80797.81 & 45436.28 & 1.28 & 348.62 \\
\hline HUR $4-3+20 \times 20 \mathrm{~cm}^{2}$ & 35256.53 & 80285.48 & 45028.95 & 1.28 & 342.86 \\
\hline HUR $4-3+25 \times 25 \mathrm{~cm}^{2}$ & 35186.53 & 85813.18 & 50626.65 & 1.44 & 384.51 \\
\hline PRH-10 + $20 \times 10 \mathrm{~cm}^{2}$ & 39382.86 & 105771.9 & 66389.08 & 1.69 & 592.76 \\
\hline PRH- $10+20 \times 20 \mathrm{~cm}^{2}$ & 38782.86 & 99118.40 & 60335.54 & 1.56 & 535.52 \\
\hline PRH-10 + $25 \times 25 \mathrm{~cm}^{2}$ & 38382.86 & 98016.09 & 59633.23 & 1.55 & 529.29 \\
\hline
\end{tabular}

diversion of photosynthates to grains (Gautam et al., 2008; Sihag et al., 2015). Direct seeding of rice at a spacing of $25 \times 25 \mathrm{~cm}^{2}$ proved significantly superior regarding grain yield $(4965.79 \mathrm{~kg} / \mathrm{ha})$ and harvested index (49.77) over other spacing. It was mainly attributed to greater number of grains/panicle, panicle length and 1000-grain weight in $25 \times 25 \mathrm{~cm}^{2}$ plant spacing. However, the spacing $25 \times 25 \mathrm{~cm}^{2}(4965.79 \mathrm{~kg} / \mathrm{ha})$ and $20 \times 10 \mathrm{~cm}^{2}(4895.10 \mathrm{~kg} / \mathrm{ha})$ had statistically comparable grain yield. Similarly, significantly higher harvest index at wider plant spacing $\left(25 \times 25 \mathrm{~cm}^{2}\right)$ over two other spacing was due to higher grain yield.

Effect of cultivar and crop geometry on economics: The higher gross return (105771.9 ₹/ha) and net return (66389.08 ₹/ha) was obtained in rice hybrid PRH-10 at closer plant spacing of $20 \times 10 \mathrm{~cm}^{2}$ over other cultivars and plant spacing combinations (Table 3). However, the maximum benefit-cost ratio (1.77) was found with growing of cultivar MTU 7029 at plant spacing of $25 \mathrm{x}$ $25 \mathrm{~cm}^{2}$; this was due to the lesser cost of cultivation in association with comparatively higher grain yield.

Effect of cultivar and crop geometry on production efficiency: The production efficiency significantly influenced due to the cultivars and plant spacing combinations (Table 3). PRH-10 at closer plant spacing $20 \times 10 \mathrm{~cm}^{2}$ obtained the maximum production efficiency (592.76 ₹/ha/day) over rest of the cultivars and plant spacing combinations which decrease towards increasing plant spacing. The fact behind this result was higher grain yield in PRH-10 in association with short growth cycle as compared other high yielding cultivars MTU 7029, HUR 105 and HUR 4-3.

\section{Conclusion}

The present study demonstrated that the cultivar PRH10 improved plant height $(119.73 \mathrm{~cm})$, LAI (4.64), panicle length $(27.92 \mathrm{~cm})$, a number of grains/panicle (178.70), test weight $(26.35 \mathrm{~g})$, grain yield (5582.32 $\mathrm{kg} / \mathrm{ha}$ ) and harvest index (53.25). Similarly, cultivar MTU 7029 performed better in a number of leaves $/ \mathrm{m}^{2}$ (1715.78) and number of effective tillers $/ \mathrm{m}^{2}$ (289.67). Amongst crop geometry $25 \times 25 \mathrm{~cm}^{2}$ improved number of leaves $/ \mathrm{m}^{2}(1527.20)$ at 90 DAS, panicle length $(24.28 \mathrm{~cm})$, number of effective tillers $/ \mathrm{m}^{2}$ (261.60), number of grains/panicle (153.60), test weight $(22.07 \mathrm{~g})$, grain yield $(4965.79 \mathrm{~kg} / \mathrm{ha})$ and harvest index (49.77) whereas; in $20 \times 10 \mathrm{~cm}^{2}$ LAI (3.22) was improved at 90 DAS. The cultivar PRH-10 at $20 \times 10 \mathrm{~cm}^{2}$ was superior regarding gross return (105771.9 ₹/ha), net return (66389.08 ₹/ha) and production efficiency $(592.76 ₹ / \mathrm{ha} /$ day $)$ and the cultivar MTU 7029 at $25 \times 25 \mathrm{~cm}^{2}$ had higher benefit cost ratio. Therefore, for getting higher net return and production efficiency cultivar PRH-10 at plant spacing $20 \times 10 \mathrm{~cm}^{2}$ can be raised in dry direct-seeded rice in Varanasi region of Eastern Uttar Pradesh.

\section{REFERENCES}

AOAC (1967). Association of Official Agricultural Chemists, methods of analysis, $11^{\text {th }}$ edn. Washington, D.C., 2004, 18-19. 
Adhikari, N.P., Mishra, B.N., Kumar, D. and Mishra, P.K. (2004). Direct and residual effect of integrated nitrogen management on productivity and soil fertility in ricewheat cropping system. In: Singh, A.K., Chopra, V.K., Das, D.K., Garg, R.N., editors. Proceedings of symposium into Geoinformatics: Applications for Sustainable Development, February 17-19, 2004. Indian Agricultural Research Institute. New Delhi; p. 292-297.

Anonymous. (2010). Agricultural statistics at a glance, Directorate of Economics and Statistics, Ministry of Agriculture, New Delhi, India.

Dadhich, R. K. and Meena R.S. (2015). Enhancement of productivity of Indian mustard (Brassica juncea L.) by foliar spray of thiourea and thioglycollic acid under different irrigation levels.Ecology, Environment and Conservation. 21 (3):pp. 131-136.

FAO. (2016). http://www.fao.org/statistics/en/

Gautam, A.K., Kumar, D., Shivay, Y.S. and Mishra, B.N. (2008). 'Influence of nitrogen levels and plant spacing on growth, productivity and quality of two inbred varieties and a hybrid of aromatic rice', Archives of Agronomy and Soil Science, 54 (5): 515 -532.

Gomez, K.A. and Gomez, A.A. (1984). Statistical procedures for agricultural research. 2nd ed. New York: John Wiley \& Sons.

Indiastat. (2016). http://www.indiastat.com/default.aspx.

Jackson, M.L. (1973). Soil chemical analysis. Prentice Hall of Ind., Pvt. Ltd., New Delhi, pp 183.

Krishna, A., Biradarpatil, N.K. and Channappagoudar, B.B. (2008). Influence of system of rice intensification (SRI) cultivation on seed yield and quality. Karnataka Journal of Agricultural Science, 21(3): 369-72.

Kumar, A., Mishra, B.N and Mishra, P.K. (2002). Effect of age of seedlings and plant density on growth and yield of hybrid rice. Annals of Agricultural Research, 23(3): 381-386.

Mahajan, G., Gill, M.S. and Singh, K. (2010). Optimizing seed rate to suppress weed sand to increase yield in aerobic direct seeded rice in North-Western Indo Gangatic plains. Journal of New Seeds, 11: 225-238.

Meena, H. Meena, R.S., Rajput, B.S. and Kumar, S. (2016). Response of bio-regulators to morphology and yield of clusterbean [Cyamopsis tetragonoloba (L.) Taub.] under different sowing environments, Journal of Applied and Natural Science, 8 (2): 715 - 718.

Meena, R. S. and Yadav R. S. (2014). Phenological Performance of Groundnut Varieties under Sowing Environments in Hyper Arid Zone of Rajasthan, India. Journal of Applied and Natural Science 6(2): 344-348.

Meena, R.S. and Yadav, R.S. (2015). Yield and profitability of groundnut (Arachishypogaea $\mathrm{L}$ ) as influenced by sowing dates and nutrient levels with different varieties. Legume Research, 38(6): 791-797.
Meena, R.S., Meena V.S., Meena, S.K., and Verma, J.P. (2015).Towards the plant stress mitigate the agricultural productivity: a book review. Journal of Cleaner Production. 102:552-553.

Meena, R.S., Yadav, R.S. and Meena, V.S. (2013). Heat unit efficiency of groundnut varieties in scattered planting with various fertility levels.The Bioscan, 8(4):11891192 .

Prasad, R., Shivay, Y.S., Kumar, D. and Sharma, S.N. (2006). Learning by doing exercises in soil fertility (A practical manual of soil fertility). Division of Agronomy. New Delhi: Indian Agricultural Research Institute. pp. 68.

Shukla, U.N., Srivastava, V.K., Singh, S., Sen, A. and Kumar, V. (2014). Growth, yield and economic potential of rice (Oryza sativa) as influenced by different age of seedlings, cultivars and weed management under system of rice intensification. Indian Journal of Agricultural Sciences, 84(5): 628-36.

Siddiqui, E.A. (1993). Rice production strategy for the $21^{\text {st }}$ Century. Oryza, 30: 186-196.

Siddiqui, M.R.H., Lakpale, R. and Tripathi, R.S. (1999). Effect of spacing and fertilizer on medium duration rice varieties. Indian Journal of Agronomy, 44(2): 310-312.

Sihag, S.K. Singh, M.K., Meena, R.S., Naga, S.R., Bahadur, S., Gaurav and Yadav, R.S. (2015). Influences of spacing on growth and yield potential of dry direct seeded rice (OryzasativaL.) cultivars. The Ecoscan (Supplement on Rice), 9(1\&2): 517-519.

Sultana, M.R., Rahman, M.M. and Rahman, M.H. (2012). Effectofrow and hill spacing on the yield performance of bororice (cv. BRRI dhan45) under aerobic system of cultivation. Journal of the Bangladesh Agricultural University, 10(1): 39-42.

Thiyagarajan, T.M., Senthil kumar, K., Bindraban, P.S., Hengsdijk, H. and Ramaswamy, S. (2002). Crop management options for increasing water productivity in rice. Journal of Agricultural Resource Management, 1: $169-181$

Uphoff, N. (2007). The system of rice intensification: using alternative cultural practices to increase rice production and profitability from existing yield potentials. International Rice Commission Newsletter, Number 55, UN. Food and Agriculture Organization, Rome.

Virmani, S.S. (1996). Hybrid rice. Advances of Agronomy, 57: $377-462$.

Walkey, A. and Black, I.A. (1947). Rapid titration method for organic carbon of soils. Soil Science, 37:29-32.

Yang, J., Peng, S., Wang, Z. and Zhu, Q. (2001). Source-sink characteristics of japonica/indica hybrid rice. International Rice Research Newsletter, 26(2): 62-63. 